\title{
Group 2 Innate Lymphoid Cells in Health and Disease
}

\author{
Brian S. Kim ${ }^{1,2}$ and David Artis ${ }^{3}$ \\ ${ }^{1}$ Division of Dermatology, Department of Medicine, Washington University School of Medicine, \\ St. Louis, Missouri 63110 \\ ${ }^{2}$ Center for the Study of Itch, Washington University School of Medicine, St. Louis, Missouri 63110 \\ ${ }^{3}$ Weill Cornell Medical College, Cornell University, New York, New York 10021 \\ Correspondence: dartis@med.cornell.edu
}

Group 2 innate lymphoid cells (ILC2s) play critical roles in anti-helminth immunity, airway epithelial repair, and metabolic homeostasis. Recently, these cells have also emerged as key players in the development of allergic inflammation at multiple barrier surfaces. ILC2s arise from common lymphoid progenitors in the bone marrow, are dependent on the transcription factors ROR $\alpha$, GATA3, and TCF-1, and produce the type 2 cytokines interleukin (IL)-4, IL-5, IL-9, and/or IL-13. The epithelial cell-derived cytokines IL-25, IL-33, and TSLP regulate the activation and effector functions of ILC2s, and recent studies suggest that their responsiveness to these cytokines and other factors may depend on their tissue environment. In this review, we focus on recent advances in our understanding of the various factors that regulate ILC2 function in the context of immunity, inflammation, and tissue repair across multiple organ systems.

nnate lymphoid cells (ILCs) are part of a family of innate immune cells that are heterogeneous in their expression of transcription factors and production of effector cytokines (Bjorkstrom et al. 2013; Spits et al. 2013). ILCs do not express cell lineage (Lin) markers associated with T cells, B cells, dendritic cells (DCs), macrophages, and granulocytes, but do express CD90 (Thy1 antigen), CD25 (interleukin [IL]2R $\alpha$ ), and CD127 (IL-7R $\alpha$ ) (Spits et al. 2013). These cells are derived from a common lymphoid progenitor, and their development is dependent on the common $\gamma$-chain $(\gamma c$ or CD132), IL-7, Notch, and the transcription factor inhibitor of DNA binding 2 (Id2) (Yokota et al. 1999; Satoh-Takayama et al. 2010; Monticelli et al. 2011; Wong et al. 2012). More recent studies indicate that the majority of ILCs are also dependent on the transcriptional repressor PLZF and that all ILC subsets arise from a $\mathrm{Lin}^{-}$ $\mathrm{Id} 2^{+} \mathrm{CD}_{127^{+}} \mathrm{CD}_{25}{ }^{-} \alpha_{4} \beta_{7}{ }^{+}$precursor (Constantinides et al. 2014; Klose et al. 2014). ILCs are currently categorized into three distinct populations based on their differential developmental requirements, expression of defined transcription factors, and their expression of cell surface markers and effector cytokines (Spits and Cupedo 2012; Fuchs and Colonna 2013; Kim et al. 2013b; Spits et al. 2013, Walker et al. 2013): group 1 ILCs (ILC1s) include classical

Editor: Ruslan M. Medzhitov

Additional Perspectives on Innate Immunity and Inflammation available at www.cshperspectives.org

Copyright (C) 2015 Cold Spring Harbor Laboratory Press; all rights reserved; doi: 10.1101/cshperspect.a016337 Cite this article as Cold Spring Harb Perspect Biol 2015;7:a016337 
NK cells and T-bet-dependent, IFN- $\gamma$-producing ILCs; ROR $\alpha$ - (Halim et al. 2012b; Wong et al. 2012), GATA3- (Hoyler et al. 2012; Klein et al. 2013), and TCF-1-dependent (Yang et al. 2013) group 2 ILCs (ILC2s) produce IL-4, IL-5, IL-9, IL-13, and/or amphiregulin (Monticelli et al. 2011); and ROR $\gamma t$-dependent group 3 ILCs (ILC3s) produce IL-17A and/or IL-22 (Fig. 1) (Sonnenberg and Artis 2012). These ILC populations are functionally analogous to the previously described $\mathrm{T}_{\mathrm{H}} 1, \mathrm{~T}_{\mathrm{H}} 2$, and $\mathrm{T}_{\mathrm{H}} 17$ $\mathrm{CD}^{+}{ }^{+} \mathrm{T}$ helper cell subsets, respectively. However, although ILCs exhibit shared functions with adaptive $\mathrm{CD} 4^{+} \mathrm{T}$ cells, they are unique in that they respond to innate signals in the absence of antigen specificity, lack T-cell receptors, and have distinct phenotypic and functional profiles.

Different subsets of ILCs promote either tissue homeostasis or detrimental inflammatory processes at multiple epithelial barrier surfaces (Monticelli et al. 2011; Sonnenberg et al. 2012; Hepworth et al. 2013; Qiu et al. 2013). Further, these cells have been implicated in a variety of different disease states including allergy, autoimmunity, cancer, infection, and obesity (Sonnenberg and Artis 2012; Kim et al. 2013b; Molofsky et al. 2013; Nussbaum et al. 2013). The roles of the ILC1 and ILC3 subsets in various diseases have been covered elsewhere (Spits and Cupedo 2012; Fuchs and Colonna 2013; Sonnenberg 2013; Sonnenberg et al. 2013; Spits et al. 2013). Therefore, in this review, we will focus primarily on the emerging role of ILC2s in both health and disease across multiple organ systems. First, we will introduce ILC2s and the context in which these cells were originally identified. Second, we will give an overview of the factors that broadly regulate ILC2s and their

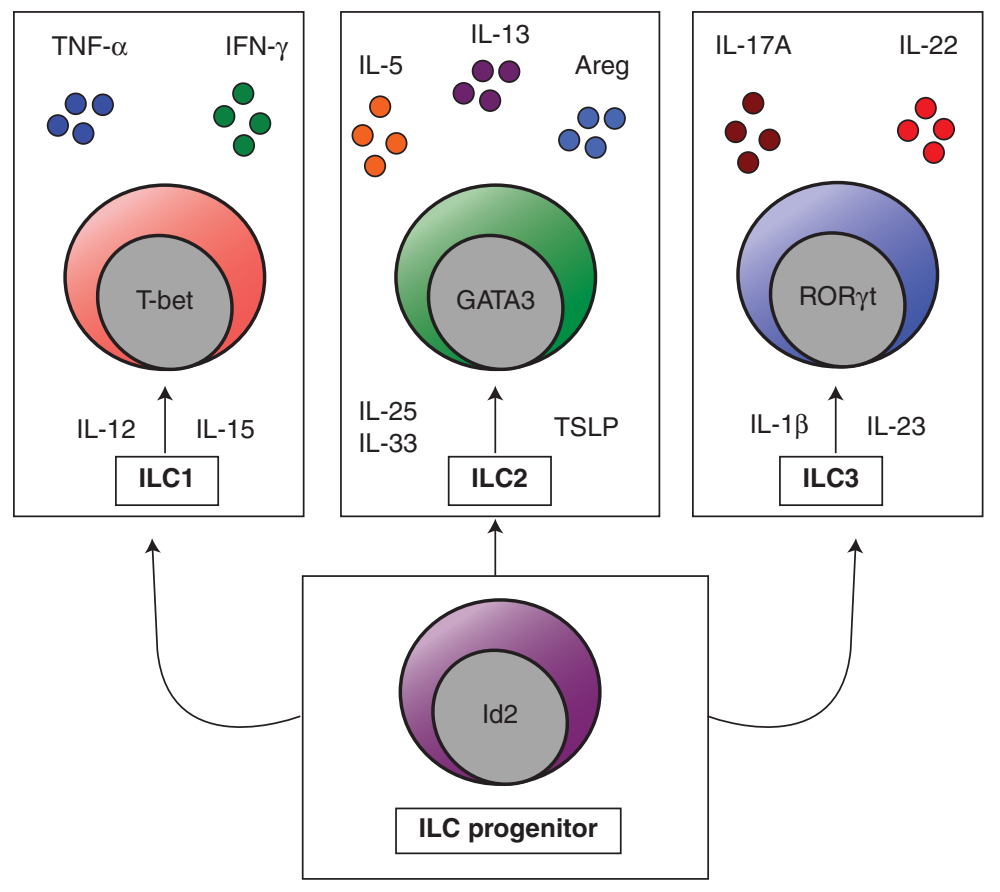

Figure 1. The innate lymphoid cell family. Innate lymphoid cells (ILCs) are a heterogeneous family of innate immune cells that arise from a common Id2-dependent lymphoid progenitor in the bone marrow. Group 1 ILCs (ILC1s) respond to IL-12 and IL-15, express the transcription factor T-bet, and produce tumor necrosis factor $\alpha$ (TNF- $\alpha$ ) and interferon $\gamma($ IFN- $\gamma$ ). Group 2 ILCs (ILC2s) respond to IL-25, IL-33, and thymic stromal lymphopoietin (TSLP), express the transcription factor GATA3, and produce IL-4, IL-5, IL-9, IL-13, and amphiregulin (Areg). Group 3 ILCs (ILC3s) respond to IL-23 and IL-1 $\beta$, express the transcription factor ROR $\gamma \mathrm{t}$, and produce IL-17A and IL-22. 
known effector functions. Finally, we will discuss recent advances in our understanding of how ILC2s contribute to both homeostasis and inflammation in a tissue-specific and disease-oriented manner.

\section{IDENTIFICATION OF ILC2s}

ILC2s were originally identified as key contributors to the development of protective immunity to the parasite Nippostrongylus brasiliensis in the gut (Fort et al. 2001; Schmitz et al. 2005; Fallon et al. 2006; Moro et al. 2010; Neill et al. 2010; Price et al. 2010). In this context, ILC2s were found to be a critical source of IL-5 and IL-13, the latter of which promotes the induction of mucous secretion from goblet cells and smooth muscle contraction that contribute to anti-helminth immunity (Moro et al. 2010; Neill et al. 2010; Price et al. 2010). These studies were the first to uncover a previously unrecognized population of ILC2s that promotes type 2 cytokine-mediated immunity. Around the same time, an ILC2-like population, named multipotent progenitor type 2 (MPP $\left.{ }^{\text {type } 2}\right)$ cells, was also identified and shown to promote type 2 cytokine-mediated immunity to helminth infection (Saenz et al. 2010). Subsequently, $\mathrm{MPP}^{\text {type2 }}$ cells have been distinguished from ILC2s by their preferential responsiveness to IL-25 rather than IL-33, their progenitor-like phenotype, and their ability to differentiate into multiple granulocyte populations (Saenz et al. 2013). Further, MPP ${ }^{\text {type2 }}$ cells exhibit distinct developmental requirements based on their Id2-independence, altered genome-wide transcriptional profiles from ILC2s, and their capacity to undergo extramedullary hematopoiesis (Saenz et al. 2013). Given that MPP ${ }^{\text {type } 2}$ cells and ILC2s are distinct populations, this review will focus specifically on the biology of ILC2s in the context of health and disease.

\section{REGULATION AND EFFECTOR FUNCTIONS OF ILC2s}

In the original studies that identified ILC2s, the epithelial cell-derived cytokines IL-25 and IL-33 were found to be potent activators of ILC2s, resulting in enhanced production of the key effector cytokines IL-5 and IL-13 (Fort et al. 2001; Schmitz et al. 2005; Fallon et al. 2006; Moro et al. 2010; Neill et al. 2010; Price et al. 2010). Subsequently, the predominantly epithelial cell-derived cytokine thymic stromal lymphopoietin (TSLP) has also been shown to be a key regulator of ILC2 function (Halim et al. 2012a; Kim et al. 2013a). Recent studies have shown that TSLP induces GATA3 expression in human ILC2s (Mjosberg et al. 2012) and promotes corticosteroid resistance to IL-33-mediated activation of ILC2s in the lung (Kabata et al. 2013). In addition, enforced expression of GATA3 in T cells and ILC2s results in elevated expression of IL-5 and IL-13 and enhanced susceptibility to allergic airway disease in mice (Kleinjan et al. 2014). These findings were consistent with prior studies by Mjosberg et al. showing that ectopic expression of GATA3 results in increased type 2 cytokine production in human ILC2s (Mjosberg et al. 2012). In addition to IL-5 and IL13 , in some circumstances, human and murine ILC2s can also produce the type 2 cytokines IL-4 and IL-9 (Wilhelm et al. 2011; Mjosberg et al. 2012; Doherty et al. 2013; Kleinjan et al. 2014). Recently, IL-9 has been shown to play a critical role in ILC2 survival in the context of lung infection with $N$. brasiliensis (Licona-Limon et al. 2013; Turner et al. 2013), suggesting that this ILC2 effector cytokine participates in a positive-feedback system. ILC2s are also a critical source of the epidermal growth factor receptor (EGFR) ligand Areg, which mediates lung epithelial repair following influenza infection (Monticelli et al. 2011). Although originally identified in association with lung ILC2s, Areg expression has also been shown in human skin ILC2s (Salimi et al. 2013). Taken together, these studies show that ILC2s are potently activated by the epithelial cell-derived cytokines IL25, IL-33, and TSLP, and produce a variety of type 2 cytokines as well as the EGFR ligand Areg in mediating both immunity and epithelial repair (Fig. 2).

The regulation of ILC2 activation and acquisition of effector functions appears to involve a complex network of signals at the epithelial barrier surface. ILC2s are elicited by a 
variety of factors such as microbial pathogens, helminth parasites, and allergens (Monticelli et al. 2012; Sonnenberg and Artis 2012). In addition to the epithelial cell-derived cytokines IL-25, IL-33, and TSLP, ILC2s express the receptors for and are activated by IL-2 (CD25) and IL-7 (CD127), indicating that they also respond to other stromal and hematopoietic cell-derived cytokines (Roediger et al. 2013). Further, ILC2s have also recently been shown to respond directly to non-cytokine molecules, including eicosanoids. Specifically, ILC2s are activated by prostaglandin $\mathrm{D}_{2}\left(\mathrm{PGD}_{2}\right)$ (Barnig et al. 2013; Chang et al. 2013; Xue et al. 2013) and leukotriene $\mathrm{D}_{4}\left(\mathrm{LTD}_{4}\right)$ (Doherty et al. 2013$)$ and are inhibited by lipoxin $\mathrm{A}_{4}\left(\mathrm{LXA}_{4}\right)$ (Barnig et al. 2013). In addition to activation, human ILC2s express the $\mathrm{PGD}_{2}$ receptor chemoattractant receptor-homologous molecule expressed on $\mathrm{T}_{\mathrm{H}} 2$ cells $(\mathrm{CRTH} 2)$ and migrate in vitro in response to $\mathrm{PGD}_{2}$ (Chang et al. 2013; Xue et al. 2013). Collectively, these studies show that ILC2s respond to a variety of signals that modulate both their cytokine production as well as chemotaxis (Fig. 2).

\section{ILC2s IN THE GUT}

ILC2s were originally identified in gastrointestinal tissue and fat-associated lymphoid clusters (FALCs), highlighting an important role for these cells in mediating protective immune responses and inflammation in the gut (Moro et al. 2010; Neill et al. 2010; Price et al. 2010). These original studies showed that IL-25- and IL-33-responsive ILC2s were critical for the development of type 2 cytokine-associated inflammation and goblet cell hyperplasia that facilitate expulsion of $N$. brasiliensis in the absence of adaptive immunity (Moro et al. 2010; Neill et al. 2010; Price et al. 2010). A more recent study has shown that IL-33 is critical for the induction of IL-13 production by ILC2s to mediate worm expulsion (Hung et al. 2013). In addition to their role in mediating protective immunity to helminth parasites, ILC2s also contribute to the development of pathologic type 2 inflammation, as they promoted gut inflammation in an IL-25-dependent fashion in a murine model of oxazalone-induced colitis (Camelo et al. 2012). In the context of food allergy, elevated IL-25, IL-33, and TSLP re-

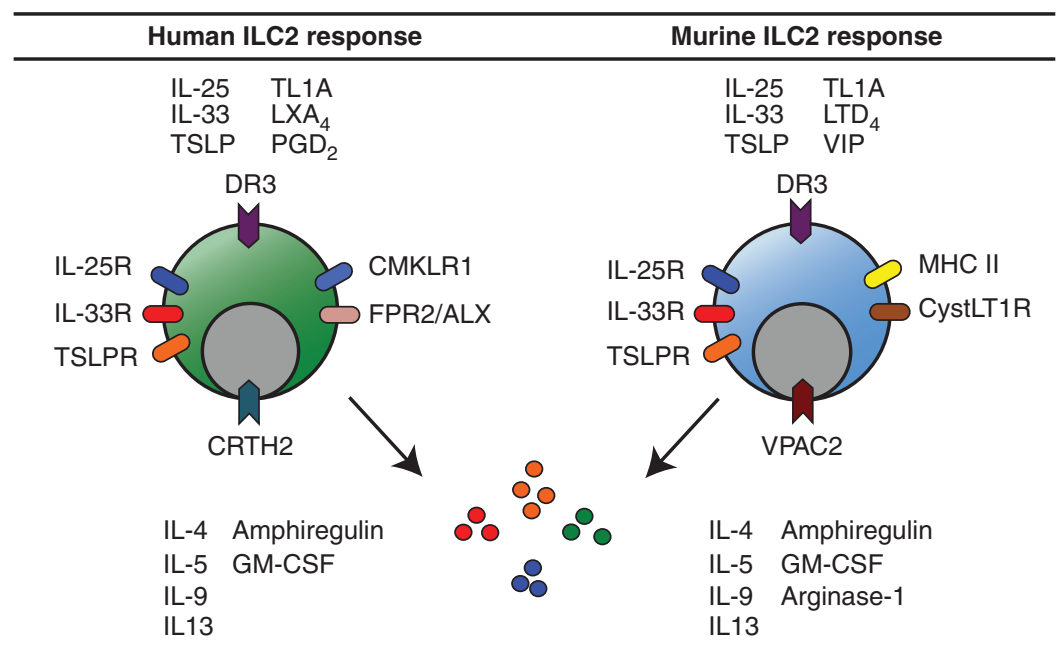

Figure 2. Regulation of human and murine ILC2 responses. Human ILC2s are activated by IL-25, IL-33, TSLP, TL1A, and prostaglandin D2 $\left(\mathrm{PGD}_{2}\right)$ and inhibited by lipoxin $\mathrm{A}_{4}\left(\mathrm{LXA}_{4}\right)$. Murine ILC2s are activated by IL-25, IL-33, TSLP, TL1A, leukotriene D4 $\left(\mathrm{LTD}_{4}\right)$, and vasoactive intestinal peptide (VIP). Both human and murine ILC2s express the receptors to respond directly to these mediators and produce IL-4, IL-5, IL-9, IL-13, granulocyte macrophage colony-stimulating factor (GM-CSF), and amphiregulin (Areg). Murine ILC2s express arginase-1. 
sponses have been observed in murine models and in patients (Blazquez et al. 2010; Herberth et al. 2010; Chu et al. 2013), provoking the hypothesis that these cytokines may promote ILC2 responses that contribute to the development of inflammation in the gut in response to food antigens through the expression of the type 2 cytokines IL-4, IL-5, and IL-13. However, the specific role of ILC2s in murine models of food allergy remains to be examined. Additionally, ILC2s have been characterized in human fetal gut and in the gut of healthy subjects as well as patients with inflammatory bowel disease (Mjosberg et al. 2011). However, accumulation of these cells in inflamed human intestinal tissue has not been shown. Further studies will be required to elucidate the role of ILC2s in promoting intestinal allergic inflammation in humans.

\section{ILC2s IN THE RESPIRATORY TRACT}

\section{ILC2s and Influenza}

Murine ILC2s in the lung were first described in murine models of influenza, where they were found to promote pathologic airway hyperreactivity (AHR) (Chang et al. 2011) as well as protective epithelial repair (Monticelli et al. 2011) in response to virus-induced lung inflammation. The latter study showed that ILC2s were a critical source of the EGFR ligand Areg in the lung following influenza virus infection, and treatment with recombinant Areg was sufficient to restore lung epithelial barrier integrity (Monticelli et al. 2011). A more recent study has shown that the interactions between ILC2s and NKT cells result in the production of IL-5 from ILC2s, which promotes the accumulation of eosinophils in the lung during the recovery phase of influenza infection (Gorski et al. 2013). However, the precise role of ILC2s in the pathogenesis of human influenza infection remains to be determined.

\section{ILC2s and Allergic Airway Inflammation}

Although ILC2s in the lung were first described in murine models of influenza (Chang et al. 2011; Monticelli et al. 2011), these cells have recently been shown to play a critical role in regulating the development of allergic airway inflammation. For example, IL-33-induced ILC2s that produce IL-13 contributed to the development of AHR in multiple murine asthma models in the absence of CD4 ${ }^{+} \mathrm{T}$ cells (Bartemes et al. 2012; Beamer et al. 2012; Doherty et al. 2012; Kim et al. 2012; Salmond et al. 2012). Similarly, in models of allergen-induced airway inflammation, IL-25-, IL-33-, and TSLPresponsive ILC2s were critical for the development of allergic airway inflammation in lymphocyte-deficient mice (Halim et al. 2012a, 2012b; Klein et al. 2012). Although all of these studies showed that lung-resident ILC2s produce the effector cytokines IL-5 and IL-13, Wilhelm et al. further showed a critical role for ILC2-derived IL-9 in the context of papain-induced lung inflammation. Induction of allergic inflammation in IL-9 reporter mice revealed that ILC2s express IL-9 in an IL-2-dependent manner, which played a critical role in promoting the survival of ILC2s and in the induction of IL-5 and IL-13 expression (Wilhelm et al. 2011). A more recent study has also shown a critical role for IL-9 in mediating ILC2 survival in the lung during infection with $N$. brasiliensis (Turner et al. 2013).

Multiple reports indicate that IL-33 is a potent activator of IL-13-producing ILC2s in allergic airway inflammation (Bartemes et al. 2012; Beamer et al. 2012; Mjosberg et al. 2012; Salmond et al. 2012; Hung et al. 2013; Shaw et al. 2013), but other epithelial cell-derived cytokines, bioactive lipids, and inflammatory factors also contribute to the development of pathogenic ILC2 responses in the lung. A recent study has shown that TSLP can contribute to ILC2 activation that promotes corticosteroid resistance in the context of IL-33-mediated airway inflammation (Kabata et al. 2013). Further, recent reports suggest that other factors, such as eicosanoids, could also play a key role in promoting ILC2 responses in the inflamed lung (Barnig et al. 2013; Doherty et al. 2013). For instance, lung ILC2s express the receptor for $\mathrm{LTD}_{4}$ and ligation of this receptor rapidly induces IL-5 production by ILC2s. This process is abrogated by montelukast, a leukotriene recep- 
tor antagonist used in the treatment of asthma (Doherty et al. 2013). In the same study, $\mathrm{LTD}_{4}$, but not IL-33, induced high levels of IL-4 production by ILC2s (Doherty et al. 2013). Furthermore, in vitro studies have shown that $\mathrm{PGD}_{2}$ derived from mast cells activates ILC2s, up-regulates expression of receptors for IL-25 (IL-17RA) and IL-33 (ST2), and induces chemotaxis of human ILC2s (Barnig et al. 2013; Chang et al. 2013; Xue et al. 2013). Furthermore, $\mathrm{LXA}_{4}$, a proresolving factor known to be decreased in severe asthma, directly inhibited $\mathrm{PGD}_{2}$-mediated activation of human ILC2s from peripheral blood (Xue et al. 2013). LXA $_{4}$ is an endogenous ligand for the receptor FPR2/ ALX and functions to limit inflammation in asthma. Importantly, $\mathrm{LXA}_{4}$ in conjunction with other proresolving receptors such as CMKLR1 was found to be expressed on human ILC2s, suggesting that these anti-inflammatory pathways may be operative on ILC2s (Barnig et al. 2013). Finally, two groups independently identified that the TNF-family cytokine TL1A promotes allergic airway inflammation and pathology in response to papain (Yu et al. 2013; Meylan et al. 2014), and that human peripheral blood ILC2s are activated by TL1A in synergy with IL-25 and IL-33 (Yu et al. 2013). These studies indicate that various epithelial cellderived cytokines might coordinately regulate ILC2 phenotype and function in inflamed tissue in conjunction with eicosinoids and TL1A. However, further studies will be required to fully characterize the factors that regulate ILC2 activation during allergic airway inflammation and the mechanisms by which these cells migrate into and out of lung tissue.

Beyond the factors that regulate pathogenic ILC2 responses during allergic airway inflammation, recent studies have identified ILC2s as novel sources of growth factors and enzymes that can regulate epithelial repair and inflammation in the lung. As mentioned above, Monticelli et al. (2011) identified that the EGFR ligand Areg critically regulates lung epithelial regeneration in the context of influenza infection (Monticelli et al. 2011). More recently, ILC2s have been shown to be a constitutive and dominant source of arginase-1 (Arg1) in healthy lung tissue (Bando et al. 2013). This was an unexpected finding, given that alternatively activated macrophages (AAMs) have traditionally been considered a significant source of Arg1, which regulates lung inflammation in asthma (Maarsingh et al. 2009; Pesce et al. 2009). However, the precise mechanisms and roles of these factors in regulating lung inflammation and repair remain poorly understood and is an active area of investigation (Fig. 3).

Although ILC2s have not been shown to accumulate in the lung of human asthmatic patients to date, numerous studies have suggested that human ILC2s in the lung could contribute to the development of allergic airway inflammation. Human lung ILC2s were first identified by flow cytometry as $\operatorname{Lin}^{-} \mathrm{CD}_{127^{+}} \mathrm{CRTH}^{+}$and $\mathrm{Lin}^{-} \mathrm{CD} 127^{+} \mathrm{CD} 25^{+} \mathrm{IL}_{-33 \mathrm{R}^{+}}$cells in healthy fetal and adult lung tissue (Mjosberg et al. 2011; Monticelli et al. 2011), and were subsequently visualized by immunofluorescence as $\mathrm{Lin}^{-} \mathrm{C}$ $\mathrm{Kit}^{+} \mathrm{CD} 161^{+}$cells (Barnig et al. 2013). Elevated expression of IL-25, IL-33, and TSLP has been shown in human asthmatic lung tissue (Prefontaine et al. 2010; Corrigan et al. 2011; Shikotra et al. 2012), and human peripheral blood ILC2s responded to asthma-associated $\mathrm{PGD}_{2}$ by producing IL-13 (Barnig et al. 2013). In addition, pathogenic $\mathrm{LTD}_{4}$-initiated lung ILC2 responses in mice were abrogated following treatment with montelukast (Doherty et al. 2013). Together, these studies suggest that ILC2s may be relevant targets in the treatment of asthma in patients. Further studies in human subjects will be required to determine whether ILC2s are directly pathogenic in human asthma and whether these cells could be targeted therapeutically.

\section{ILC2s and Other Lung Diseases}

Although the identification of ILC2s has generated significant interest in their role in allergic airway inflammation, ILC2s have been implicated in other pathologic pulmonary processes in humans. A recent study in patients with eosinophilic pleural effusion (EPE) associated with primary spontaneous pneumothorax (PSP) reported elevated expression of TSLP and IL-33 in the pleural fluid along with elevat- 


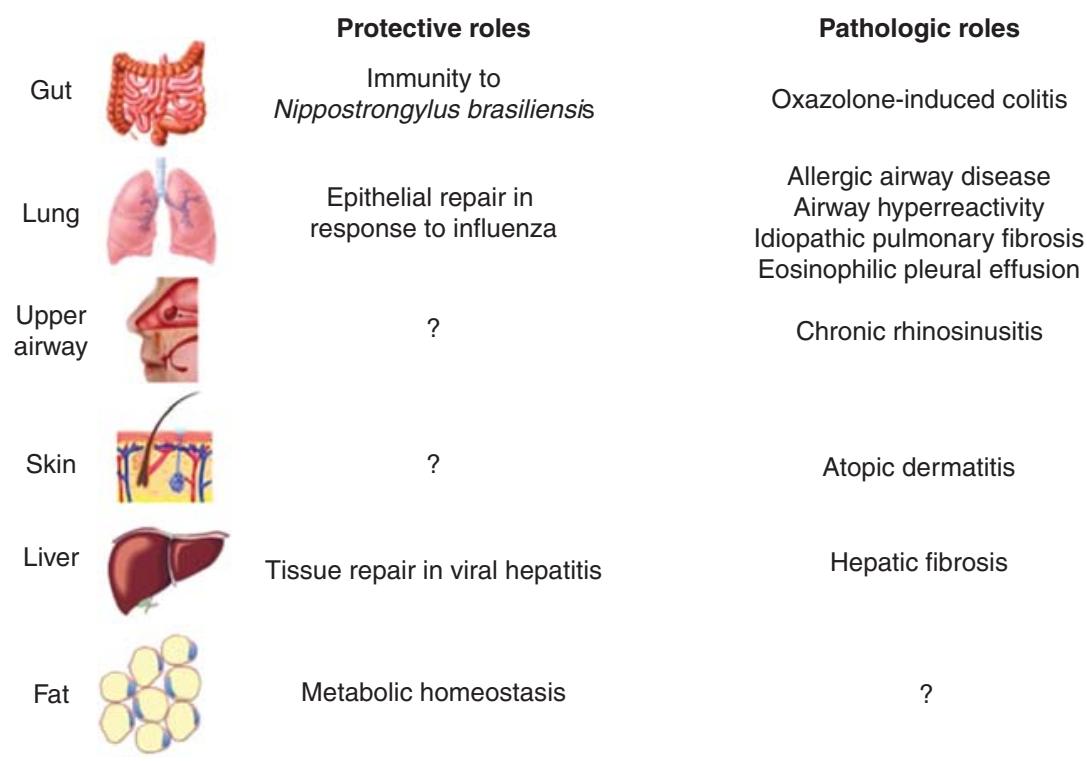

Figure 3. Protective versus pathogenic roles of ILC2s. Gut-associated ILC2s play an essential role in protective immunity to helminth parasites and can promote type 2 inflammatory colitis. Lung ILC2s have shown a protective role by mediating epithelial repair in response to influenza virus infection. Further, they have shown pathogenic roles by promoting allergic airway disease, airway hyperreactivity, and pulmonary fibrosis and have been implicated in eosinophilic pleural effusion. ILC2s in the upper airway have been implicated in chronic rhinosinusitis and found in the nasal poylps of patients. Skin ILC2s are highly enriched in atopic dermatitis (AD) lesions and promote AD-like disease in murine models. ILC2s in the liver have been shown to promote tissue repair in response to viral-induced injury as well as pathogenic fibrosis. ILC2s in white adipose tissue regulate metabolic homeostasis via cellular interactions with eosinophils and alternatively activated macrophages.

ed IL-5, eotaxin-3, and enhanced ILC2 responses (Kwon et al. 2013). This study provokes the hypothesis that ILC2s may be the key driver of eosinophilia in the context of EPE and PSP. Another recent study used a Schistosoma mansoni egg-induced model of pulmonary fibrosis to identify that IL-25 is a key mediator of this disease in mice (Hams et al. 2014). Further investigation identified that IL-13-expressing ILC2s were both necessary and sufficient to induce pulmonary fibrosis in mice and that $\mathrm{Lin}^{-}$ $\mathrm{CD}_{127^{+}} \mathrm{CRTH}_{2}{ }^{+} \mathrm{IL} 33 \mathrm{R}^{+}$ILC2s were significantly enriched in the broncheoalveolar lavage fluid (BALF) of patients with idiopathic pulmonary fibrosis (IPF) (Hams et al. 2014). Collectively, these studies indicate that ILC2s may play different roles across multiple disease states in the lung including influenza, allergic airway disease, PSP, and IPF (Fig. 3).

\section{Chronic Rhinosinusitis}

Chronic rhinosinusitis (CRS) is a common complication arising from allergic rhinitis and, when associated with nasal polyps, is strongly associated with type 2 cytokine production in the nasal mucosa. CRS was the first human disease in which an accumulation of $\mathrm{Lin}^{-}$ $\mathrm{CRTH}_{2}{ }^{+} \mathrm{CD}_{161}{ }^{+}$ILC2s in inflamed tissue was clearly shown (Mjosberg et al. 2011). ILC2s in nasal polyps of CRS patients were originally identified as being responsive to IL-25 and IL-33, and were subsequently shown to respond to TSLP (Mjosberg et al. 2012). These studies also highlighted that human ILC2s produce IL-4, IL-5, IL-9, and IL-13, and express the TSLP receptor (TSLPR) (Mjosberg et al. 2012). A recent report confirmed that ILC2s are enriched in ethmoid sinus mucosa of pa- 
tients with CRS and nasal polyps in comparison to control CRS patients without nasal polyps (Shaw et al. 2013). This study also showed that the ILC2s from CRS patients responded to IL-33-mediated stimulation by producing IL-13 (Shaw et al. 2013), further suggesting that ILC2s may contribute to the pathogenesis of allergic upper airway disease in humans. Consistent with previous findings (Mjosberg et al. 2012), TSLP has recently been shown to be highly expressed in the nasal polyps of CRS patients (Nagarkar et al. 2013). Although IL-33 appears to be more potent than TSLP in activating type 2 cytokine production from nasal polyp ILC2s (Mjosberg et al. 2012), further studies will be required to determine which cytokines optimally promote ILC2-mediated inflammation in CRS and whether these cells have a causal role in the development of nasal polyps or pathology in CRS patients.

\section{ILC2s IN THE SKIN}

\section{Atopic Dermatitis}

In addition to the role of ILC2s in promoting inflammation in the gut and lung, multiple studies have now shown that these cells also promote allergic inflammation in the skin. Lesional human $\mathrm{AD}$ skin has elevated expression of epithelial cell-derived cytokines that promote ILC2 responses including IL-25, IL-33, and TSLP (Soumelis et al. 2002; Hvid et al. 2011; Deleuran et al. 2012; Savinko et al. 2012), and ILC2s have been identified in both murine and human skin and are enriched in the lesional skin of human AD patients (Kim et al. 2013a; Roediger et al. 2013). Although IL-33 has emerged as the dominant cytokine in the activation of ILC2s from murine lung (Barlow et al. 2013), human blood, and nasal polyps (Mjosberg et al. 2012), the original studies identifying skin ILC2s found that murine skin ILC2s are IL33- and IL-25-independent but dependent on TSLP for their activation during murine AD-like disease (Kim et al. 2013a). Further, skin-associated ILC2s could directly induce AD-like pathology and $\mathrm{T}_{\mathrm{H}} 2$ cell responses in vivo (Kim et al. 2013a). A more recent study confirmed the presence of ILC2s in murine skin and used transgenic mice overexpressing IL-33 under a keratin 14 promoter to show that IL-33 expression can also drive AD-like inflammation and the expansion of ILC2s in the skin (Imai et al. 2013). Recently, Salimi et al. (2013) confirmed that skin ILC2s are dependent on TSLP in C57BL/ 6 mice and found that there is partial dependence on both IL-25 and IL-33 in the development of skin ILC2 responses in BALB/ c (but not C57BL/6) mice during AD-like inflammation. They also showed the presence of ILC2s in human skin and their enrichment in lesional AD skin (Salimi et al. 2013). Further, they found that human skin ILC2s up-regulate expression of both type 2 cytokines and Areg in response to IL-33 (Salimi et al. 2013). Finally, recent work has also focused on the cellular interactions and migratory patterns of skin ILC2s. Roediger et al. used intravital multiphoton microscopy to directly visualize skin ILC2s and characterize their interactions with skinresident mast cells (Roediger et al. 2013). In these studies, skin ILC2s were found to constitutively express IL-13, produce IL-5 in response to IL-2-mediated activation, and modulate cutaneous mast cell responses (Roediger et al. 2013). Collectively, these studies show that skin ILC2s promote type 2 cytokine-associated skin inflammation and coordinately interact with other innate and adaptive cells in the skin to influence their function (Fig. 4). However, further studies will be required to fully assess the factors that promote and regulate ILC2-mediated skin inflammation.

\section{ILC2s IN METABOLIC TISSUES}

\section{ILC2s in the Liver}

Although the importance of ILC2 responses at mucosal barriers such as the gut and lung has been appreciated, ILC2 responses have also been characterized in other organs that regulate metabolic homeostasis such as the liver and adipose tissue. The liver is a critical regulator of glucose metabolism, whereas the adipose tissue is a regulator of lipid homeostasis. In the context of liver disease, patients with cir- 
Group 2 Innate Lymphoid Cells

rhosis and mice with $\mathrm{CCL}_{4}$-induced hepatic fibrosis had significantly higher levels of IL-33 in the serum in comparison to controls (McHedlidze et al. 2013). Based on these findings, McHedlidze et al. (2013) showed that IL-33 mediates hepatic fibrogenesis in mice via ILC2s. They also identified that human cirrhotic livers have higher expression of IL-13 receptor components, suggesting that ILC2-derived IL-13 may be a key mediator of hepatic fibrosis in humans as well (McHedlidze et al. 2013). Another recent study identified that IL-33 attenuates liver damage in the context of adenovirus-induced hepatitis in mice, possibly through the ability of IL-33-dependent ILC2s to limit TNF- $\alpha$ production from hepatic T cells and macrophages (Liang et al. 2013). Adoptive transfer studies also suggested that ILC2s might mediate liver protection in vivo in response to viral hepatitis (Liang et al. 2013). However, the precise mechanisms by which ILC2s are protective in the liver remain to be determined. Collectively, these studies indicate that IL-33dependent ILC2s can have either beneficial or detrimental effects on liver homeostasis depending on the context of liver injury (Fig. 3). Future studies will be required to determine the effector mechanisms by which ILC2s mediate these processes.

\section{ILC2s in White Adipose Tissue}

Recent work has highlighted a previously unappreciated role for ILC2s in mediating metabolic homeostasis in adipose tissue. Type 2 cytokine-associated eosinophil responses regulate AAMs to promote glucose and adipose tissue homeostasis (Wu et al. 2011) and ILC2s have recently been shown to regulate this process via production of IL-5 and its effect on eosinophil survival (Fig. 4) (Molofsky et al. 2013). In support of these findings, IL-33 was shown to limit obesity in mice (Miller et al. 2010), whereas another study showed that IL-25 elicits ILC2s to limit obesity (Hams et al. 2013). Similarly, depletion of ILC2s led to enhanced weight gain in lymphocyte-deficient $\mathrm{Ragl}^{-/-}$mice and loss of eosinophil and AAMs populations in the visceral adipose tissue (VAT) in response to a high fat diet (Hams et al. 2013; Molofsky et al. 2013). These findings were further explored in a study by Nussbaum et al., which reported that serum levels of IL-5 and blood eosinophils correlated with circadian variation (Nussbaum et al. 2013). In addition, this study showed that ILC2 responses in the small intestine were enhanced in response to caloric input as determined by IL-13 expression (Nussbaum et al. 2013), suggesting that ILC2s may respond di-

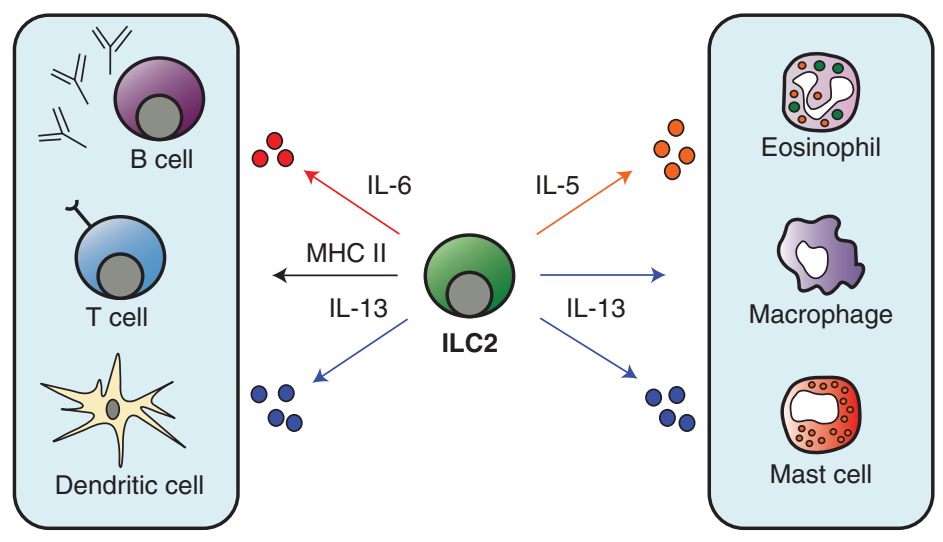

Figure 4. Effector functions of ILC2s. ILC2s in the lung have been proposed to promote adaptive CD4 ${ }^{+}$T-cell and B-cell responses via MHC class II-mediated antigen presentation and IL-6 production, respectively. Further, IL-13 has been shown to promote $\mathrm{CD}^{+}$T-cell responses indirectly via acting on dendritic cells. ILC2-derived IL-5 promotes eosinophil responses and IL-13 can regulate alternatively activated macrophage and mast cell functions. 
rectly to signals that regulate feeding and circadian rhythms. In support of this hypothesis, ILC2s were shown to express VPAC2, the receptor for vasoactive intestinal peptide (VIP), a neuropeptide that is abundant in the intestine and tightly regulated by both feeding and circadian rhythms. Additionally, ILC2s were shown to produce IL-5 in response to both VIP and a VPAC2 agonist in vitro (Nussbaum et al. 2013). Collectively, these studies suggest that metabolic and circadian cues can influence ILC2 responses and their production of IL-5 and IL-13, which in turn regulate eosinophils and AAMs in the context of metabolic homeostasis (Fig. 4). Further studies will be required to fully dissect the mechanisms by which ILC2 responses regulate metabolic homeostasis and contribute to the development of various metabolic diseases.

\section{CONCLUSIONS AND FUTURE DIRECTIONS}

Originally described in the context of anti-helminth immunity, ILC2s appear to have diverse functions at multiple barrier surfaces including the upper and lower airways, skin, and gut (Fig. 3) (Tait Wojno and Artis 2012). Further, ILC2s have also been identified in multiple other tissues including the brain, heart, kidney, muscle, liver, and adipose tissue (Hams et al. 2013; Liang et al. 2013; McHedlidze et al. 2013; Molofsky et al. 2013; Nussbaum et al. 2013). However, there are a number of questions that remain regarding the function of ILC2s. For example, the potential tissue-specific factors that regulate ILC2s are complex and remain poorly understood. The current body of evidence suggests that IL-33 may be the dominant cytokine for the activation of lung and airway ILC2s (Mjosberg et al. 2012; Monticelli et al. 2012; Barlow et al. 2013), whereas IL-25 is critical for their role in gut inflammation (Camelo et al. 2012). However, IL-25 may also play a role in the regulation of pulmonary fibrosis (Hams et al. 2014). In the skin, ILC2s have been shown to be predominantly regulated by TSLP during AD-like disease (Kim et al. 2013a). However, recent studies showed that IL-25 and IL-33 may also have relevant roles in $\mathrm{AD}$-like inflammation (Imai et al. 2013; Salimi et al. 2013). Collectively, whether IL-25, IL-33, or TSLP is the dominant cytokine for the activation and/or elicitation of ILC2s at different barrier surfaces remains to be determined.

Beyond epithelial cell-derived cytokine regulation, ILC2 activation and migration also appear to be regulated by other factors, such as TL1A (Yu et al. 2013; Meylan et al. 2014) and eicosanoids (Barnig et al. 2013; Chang et al. 2013; Doherty et al. 2013; Xue et al. 2013) in the intestine and lung, respectively. In the intestine, VIP, which is heavily influenced by caloric intake and circadian rhythms, has also been shown to activate cytokine production from ILC2s (Nussbaum et al. 2013). Furthermore, ILC2s are a novel source of growth factors (e.g., Areg) and enzymes (e.g., Arg1) that may regulate epithelial repair and inflammation at barrier surfaces (Monticelli et al. 2011; Bando et al. 2013). These newer studies show that the regulation and function of ILC2s may be much more complex than previously recognized.

Moreover, recent studies have shown that ILC2s interact with and/or regulate other innate cell populations such as mast cells (Roediger et al. 2013), eosinophils (Nussbaum et al. 2013), and macrophages (Molofsky et al. 2013), as well as adaptive $\mathrm{T}_{\mathrm{H}} 2$ cell responses via type 2 cytokine-mediated activation of DCs (Fig. 4) (Halim et al. 2014). Additionally, MHC class II-mediated antigen presentation by ILC2s has been recently shown to induce $\mathrm{CD} 4^{+} \mathrm{T}$ cell proliferation (Mirchandani et al. 2014). Thus, understanding how ILC2s regulate type 2 cytokine-associated inflammation through interactions with various innate and adaptive cell populations is an emerging field of great interest. Further, the role ILC2s play in food allergy and other allergic diseases that influence epithelial barriers, such as urticaria, eosinophilic gastrointestinal diseases, and anaphylaxis, remains to be explored. Future studies aimed at understanding the regulation and effector mechanisms of human ILC2s in different organ systems will be critical to developing therapeutics that target ILC2s to treat multiple inflammatory diseases. 


\section{REFERENCES}

Bando JK, Nussbaum JC, Liang HE, Locksley RM. 2013. Type 2 innate lymphoid cells constitutively express arginase-I in the naïve and inflamed lung. J Leukoc Biol 94: 877-884.

Barlow JL, Peel S, Fox J, Panova V, Hardman CS, Camelo A, Bucks C, Wu X, Kane CM, Neill DR, et al. 2013. IL-33 is more potent than IL-25 in provoking IL13-producing nuocytes (type 2 innate lymphoid cells) and airway contraction. $J$ Allergy Clin Immunol 132: 933-941.

Barnig C, Cernadas M, Dutile S, Liu X, Perrella MA, Kazani S, Wechsler ME, Israel E, Levy BD. 2013. Lipoxin $\mathrm{A}_{4}$ regulates natural killer cell and type 2 innate lymphoid cell activation in asthma. Sci Transl Med 5: 174 ra126.

Bartemes KR, Iijima K, Kobayashi T, Kephart GM, McKenzie AN, Kita H. 2012. IL-33-responsive lineage ${ }^{-}$CD $25^{+}$ CD44 ${ }^{\text {hi }}$ lymphoid cells mediate innate type 2 immunity and allergic inflammation in the lungs. J Immunol 188: 1503-1513.

Beamer CA, Girtsman TA, Seaver BP, Finsaas KJ, Migliaccio CT, Perry VK, Rottman JB, Smith DE, Holian A. 2012. IL33 mediates multi-walled carbon nanotube (MWCNT)induced airway hyper-reactivity via the mobilization of innate helper cells in the lung. Nanotoxicology 7: 10701081.

Bjorkstrom NK, Kekalainen E, Mjosberg J. 2013. Tissuespecific effector functions of innate lymphoid cells. Immunology 139: 416-427.

Blazquez AB, Mayer L, Berin MC. 2010. Thymic stromal lymphopoietin is required for gastrointestinal allergy but not oral tolerance. Gastroenterology 139: 1301-1309.

Camelo A, Barlow JL, Drynan LF, Neill DR, Ballantyne SJ, Wong SH, Pannell R, Gao W, Wrigley K, Sprenkle J, et al. 2012. Blocking IL-25 signalling protects against gut inflammation in a type- 2 model of colitis by suppressing nuocyte and NKT derived IL-13. J Gastroenterol 47: 1198-1211.

Chang YJ, Kim HY, Albacker LA, Baumgarth N, McKenzie AN, Smith DE, Dekruyff RH, Umetsu DT. 2011. Innate lymphoid cells mediate influenza-induced airway hyperreactivity independently of adaptive immunity. Nat Immunol 12: 631-638.

Chang JE, Doherty TA, Baum R, Broide D. 2013. Prostaglandin D2 regulates human type 2 innate lymphoid cell chemotaxis. J Allergy Clin Immunol 133: 899-901.

Chu DK, Llop-Guevara A, Walker TD, Flader K, Goncharova S, Boudreau JE, Moore CL, Seunghyun In T, Waserman S, Coyle AJ, et al. 2013. IL-33, but not thymic stromal lymphopoietin or IL-25, is central to mite and peanut allergic sensitization. J Allergy Clin Immunol 131: e181-188.

Constantinides MG, McDonald BD, Verhoef PA, Bendelac A. 2014. A committed precursor to innate lymphoid cells. Nature 508: 397-401.

Corrigan CJ, Wang W, Meng Q, Fang C, Eid G, Caballero MR, Lv Z, An Y, Wang YH, Liu YJ, et al. 2011. Allergeninduced expression of IL-25 and IL-25 receptor in atopic asthmatic airways and late-phase cutaneous responses. $J$ Allergy Clin Immunol 128: 116-124.
Deleuran M, Hvid M, Kemp K, Christensen GB, Deleuran B, Vestergaard C. 2012. IL-25 induces both inflammation and skin barrier dysfunction in atopic dermatitis. Chem Immunol Allergy 96: 45-49.

Doherty TA, Khorram N, Chang JE, Kim HK, Rosenthal P, Croft M, Broide DH. 2012. STAT6 regulates natural helper cell proliferation during lung inflammation initiated by Alternaria. Am J Physiol Lung Cell Mol Physiol 303: L577-588.

Doherty TA, Khorram N, Lund S, Mehta AK, Croft M, Broide DH. 2013. Lung type 2 innate lymphoid cells express cysteinyl leukotriene receptor 1 , which regulates T2 cytokine production. J Allergy Clin Immunol 132: 205-213.

Fallon PG, Ballantyne SJ, Mangan NE, Barlow JL, Dasvarma A, Hewett DR, McIlgorm A, Jolin HE, McKenzie AN. 2006. Identification of an interleukin (IL)-25-dependent cell population that provides IL-4, IL-5, and IL-13 at the onset of helminth expulsion. J Exp Med 203: 1105-1116.

Fort MM, Cheung J, Yen D, Li J, Zurawski SM, Lo S, Menon S, Clifford T, Hunte B, Lesley R, et al. 2001. IL-25 induces IL-4, IL-5, and IL-13 and Th2-associated pathologies in vivo. Immunity 15: 985-995.

Fuchs A, Colonna M. 2013. Innate lymphoid cells in homeostasis, infection, chronic inflammation and tumors of the gastrointestinal tract. Curr Opin Gastroenterol 29: 581-587.

Gorski SA, Hahn YS, Braciale TJ. 2013. Group 2 innate lymphoid cell production of IL-5 is regulated by NKT cells during influenza virus infection. PLoS Pathog 9: e1003615.

Halim TY, Krauss RH, Sun AC, Takei F. 2012a. Lung natural helper cells are a critical source of Th2 cell-type cytokines in protease allergen-induced airway inflammation. Immunity 36: 451-463.

Halim TY, MacLaren A, Romanish MT, Gold MJ, McNagny KM, Takei F. 2012b. Retinoic-acid-receptor-related orphan nuclear receptor $\alpha$ is required for natural helper cell development and allergic inflammation. Immunity 37: $463-474$.

Halim TY, Steer CA, Matha L, Gold MJ, Martinez-Gonzalez I, McNagny KM, McKenzie AN, Takei F. 2014. Group 2 innate lymphoid cells are critical for the initiation of adaptive T helper 2 cell-mediated allergic lung inflammation. Immunity 40: 425-435.

Hams E, Locksley RM, McKenzie AN, Fallon PG. 2013. Cutting edge: IL-25 elicits innate lymphoid type 2 and type II NKT cells that regulate obesity in mice. J Immunol 191: 5349-5353.

Hams E, Armstrong ME, Barlow JL, Saunders SP, Schwartz C, Cooke G, Fahy RJ, Crotty TB, Hirani N, Flynn RJ, et al. 2014. IL-25 and type 2 innate lymphoid cells induce pulmonary fibrosis. Proc Natl Acad Sci 111: 367-372.

Hepworth MR, Monticelli LA, Fung TC, Ziegler CG, Grunberg S, Sinha R, Mantegazza AR, Ma HL, Crawford A, Angelosanto JM, et al. 2013. Innate lymphoid cells regulate $\mathrm{CD} 4^{+} \mathrm{T}$-cell responses to intestinal commensal bacteria. Nature 498: 113-117.

Herberth G, Daegelmann C, Roder S, Behrendt H, Kramer U, Borte M, Heinrich J, Herbarth O, Lehmann I. 2010. IL17E but not IL-17A is associated with allergic sensitiza- 
tion: Results from the LISA study. Pediatr Allergy Immunol 21: 1086-1090.

Hoyler T, Klose CS, Souabni A, Turqueti-Neves A, Pfeifer D, Rawlins EL, Voehringer D, Busslinger M, Diefenbach A. 2012. The transcription factor GATA-3 controls cell fate and maintenance of type 2 innate lymphoid cells. Immunity 37: 634-648.

Hung LY, Lewkowich IP, Dawson LA, Downey J, Yang Y, Smith DE, Herbert DR. 2013. IL-33 drives biphasic IL13 production for noncanonical type 2 immunity against hookworms. Proc Natl Acad Sci 110: 282-287.

Hvid M, Vestergaard C, Kemp K, Christensen GB, Deleuran B, Deleuran M. 2011. IL-25 in atopic dermatitis: A possible link between inflammation and skin barrier dysfunction? J Invest Dermatol 131: 150-157.

Imai Y, Yasuda K, Sakaguchi Y, Haneda T, Mizutani H, Yoshimoto T, Nakanishi K, Yamanishi K. 2013. Skin-specific expression of IL-33 activates group 2 innate lymphoid cells and elicits atopic dermatitis-like inflammation in mice. Proc Natl Acad Sci 110: 13921-13926.

Kabata H, Moro K, Fukunaga K, Suzuki Y, Miyata J, Masaki K, Betsuyaku T, Koyasu S, Asano K. 2013. Thymic stromal lymphopoietin induces corticosteroid resistance in natural helper cells during airway inflammation. Nat Commun 4: 2675.

Kim HY, Chang YJ, Subramanian S, Lee HH, Albacker LA, Matangkasombut P, Savage PB, McKenzie AN, Smith DE, Rottman JB, et al. 2012. Innate lymphoid cells responding to IL-33 mediate airway hyperreactivity independently of adaptive immunity. J Allergy Clin Immunol 129: 216227.

Kim BS, Siracusa MC, Saenz SA, Noti M, Monticelli LA, Sonnenberg GF, Hepworth MR, Van Voorhees AS, Comeau MR, Artis D. 2013a. TSLP elicits IL-33-independent innate lymphoid cell responses to promote skin inflammation. Sci Transl Med 5: 170ra116.

Kim BS, Wojno ED, Artis D. 2013b. Innate lymphoid cells and allergic inflammation. Curr Opin Immunol 25: 738 744.

Kleinjan A, Klein Wolterink RG, Levani Y, de Bruijn MJ Hoogsteden HC, van Nimwegen M, Hendriks RW. 2014. Enforced expression of Gata3 in T cells and group 2 innate lymphoid cells increases susceptibility to allergic airway inflammation in mice. J Immunol 192: $1385-$ 1394.

Klein Wolterink RG, Kleinjan A, van Nimwegen M, Bergen I, de Bruijn M, Levani Y, Hendriks RW. 2012. Pulmonary innate lymphoid cells are major producers of IL-5 and IL13 in murine models of allergic asthma. Eur J Immunol 42: $1106-1116$.

Klein Wolterink RG, Serafini N, van Nimwegen M, Vosshenrich CA, de Bruijn MJ, Fonseca Pereira D, Veiga Fernandes H, Hendriks RW, Di Santo JP. 2013. Essential, dose-dependent role for the transcription factor Gata3 in the development of IL- $5^{+}$and IL- $13^{+}$type 2 innate lymphoid cells. Proc Natl Acad Sci 110: 10240-10245.

Klose CS, Flach M, Mohle L, Rogell L, Hoyler T, Ebert K, Fabiunke C, Pfeifer D, Sexl V, Fonseca-Pereira D, et al. 2014. Differentiation of type 1 ILCs from a common progenitor to all helper-like innate lymphoid cell lineages. Cell 157: 340-356.
Kwon BI, Hong S, Shin K, Choi EH, Hwang JJ, Lee SH. 2013. Innate type 2 immunity is associated with eosinophilic pleural effusion in primary spontaneous pneumothorax Am J Respir Crit Care Med 188: 577-585.

Liang Y, Jie Z, Hou L, Aguilar-Valenzuela R, Vu D, Soong L, Sun J. 2013. IL-33 induces nuocytes and modulates liver injury in viral hepatitis. J Immunol 190: 5666-5675.

Licona-Limon P, Henao-Mejia J, Temann AU, Gagliani N, Licona-Limon I, Ishigame H, Hao L, Herbert DR, Flavell RA. 2013. Th9 cells drive host immunity against gastrointestinal worm infection. Immunity 39: 744-757.

Maarsingh H, Zaagsma J, Meurs H. 2009. Arginase: A key enzyme in the pathophysiology of allergic asthma opening novel therapeutic perspectives. Br J Pharmacol 158: 652-664.

McHedlidze T, Waldner M, Zopf S, Walker J, Rankin AL, Schuchmann M, Voehringer D, McKenzie AN, Neurath MF, Pflanz S, et al. 2013. Interleukin-33-dependent innate lymphoid cells mediate hepatic fibrosis. Immunity 39: 357-371.

Meylan F, Hawley ET, Barron L, Barlow JL, Penumetcha P, Pelletier M, Sciume G, Richard AC, Hayes ET, GomezRodriguez J, et al. 2014. The TNF-family cytokine TL1A promotes allergic immunopathology through group 2 innate lymphoid cells. Mucosal Immunol 7: 958-968.

Miller AM, Asquith DL, Hueber AJ, Anderson LA, Holmes WM, McKenzie AN, Xu D, Sattar N, McInnes IB, Liew FY. 2010. Interleukin-33 induces protective effects in adipose tissue inflammation during obesity in mice. Circ Res 107: 650-658.

Mirchandani AS, Besnard AG, Yip E, Scott C, Bain CC, Cerovic V, Salmond RJ, Liew FY. 2014. Type 2 innate lymphoid cells drive $\mathrm{CD} 4{ }^{+} \mathrm{Th} 2$ cell responses. J Immunol 192: $2442-2448$.

Mjosberg JM, Trifari S, Crellin NK, Peters CP, van Drunen CM, Piet B, Fokkens WJ, Cupedo T, Spits H. 2011. Human IL-25- and IL-33-responsive type 2 innate lymphoid cells are defined by expression of CRTH2 and CD161. Nat Immunol 12: 1055-1062.

Mjosberg J, Bernink J, Golebski K, Karrich JJ, Peters CP, Blom B, te Velde AA, Fokkens WJ, van Drunen CM, Spits H. 2012. The transcription factor GATA3 is essential for the function of human type 2 innate lymphoid cells. Immunity 37: 649-659.

Molofsky AB, Nussbaum JC, Liang HE, Van Dyken SJ, Cheng LE, Mohapatra A, Chawla A, Locksley RM. 2013. Innate lymphoid type 2 cells sustain visceral adipose tissue eosinophils and alternatively activated macrophages. J Exp Med 210: 535-549.

Monticelli LA, Sonnenberg GF, Abt MC, Alenghat T, Ziegler CG, Doering TA, Angelosanto JM, Laidlaw BJ, Yang CY, Sathaliyawala T, et al. 2011. Innate lymphoid cells promote lung-tissue homeostasis after infection with influenza virus. Nat Immunol 12: 1045-1054.

Monticelli LA, Sonnenberg GF, Artis D. 2012. Innate lymphoid cells: Critical regulators of allergic inflammation and tissue repair in the lung. Curr Opin Immunol 24: 284-289.

Moro K, Yamada T, Tanabe M, Takeuchi T, Ikawa T, Kawamoto H, Furusawa J, Ohtani M, Fujii H, Koyasu S. 2010. Innate production of $\mathrm{T}_{\mathrm{H}} 2$ cytokines by adipose tissue- 
associated $\mathrm{c}-\mathrm{Kit}^{+} \mathrm{Sca}-1^{+}$lymphoid cells. Nature 463: $540-544$.

Nagarkar DR, Poposki JA, Tan BK, Comeau MR, Peters AT, Hulse KE, Suh LA, Norton J, Harris KE, Grammer LC, et al. 2013. Thymic stromal lymphopoietin activity is increased in nasal polyps of patients with chronic rhinosinusitis. J Allergy Clin Immunol 132: 593-600.

Neill DR, Wong SH, Bellosi A, Flynn RJ, Daly M, Langford TK, Bucks C, Kane CM, Fallon PG, Pannell R, et al. 2010. Nuocytes represent a new innate effector leukocyte that mediates type-2 immunity. Nature 464: 1367-1370.

Nussbaum JC, Van Dyken SJ, von Moltke J, Cheng LE, Mohapatra A, Molofsky AB, Thornton EE, Krummel MF, Chawla A, Liang HE, et al. 2013. Type 2 innate lymphoid cells control eosinophil homeostasis. Nature 502: 245-248.

Pesce JT, Ramalingam TR, Mentink-Kane MM, Wilson MS El Kasmi KC, Smith AM, Thompson RW, Cheever AW, Murray PJ, Wynn TA. 2009. Arginase-1-expressing macrophages suppress Th2 cytokine-driven inflammation and fibrosis. PLoS Pathog 5: e1000371.

Prefontaine D, Nadigel J, Chouiali F, Audusseau S, Semlali A, Chakir J, Martin JG, Hamid Q. 2010. Increased IL-33 expression by epithelial cells in bronchial asthma. J Allergy Clin Immunol 125: 752-754.

Price AE, Liang HE, Sullivan BM, Reinhardt RL, Eisley CJ, Erle DJ, Locksley RM. 2010. Systemically dispersed innate IL-13-expressing cells in type 2 immunity. Proc Natl Acad Sci 107: 11489-11494.

Qiu J, Guo X, Chen ZM, He L, Sonnenberg GF, Artis D, Fu YX, Zhou L. 2013. Group 3 innate lymphoid cells inhibit T-cell-mediated intestinal inflammation through aryl hydrocarbon receptor signaling and regulation of microflora. Immunity 39: 386-399.

Roediger B, Kyle R, Yip KH, Sumaria N, Guy TV, Kim BS, Mitchell AJ, Tay SS, Jain R, Forbes-Blom E, et al. 2013. Cutaneous immunosurveillance and regulation of inflammation by group 2 innate lymphoid cells. Nat Immunol 14: 564-573.

Saenz SA, Siracusa MC, Perrigoue JG, Spencer SP, Urban JF Jr, Tocker JE, Budelsky AL, Kleinschek MA, Kastelein RA, Kambayashi T, et al. 2010. IL25 elicits a multipotent progenitor cell population that promotes $\mathrm{T}_{\mathrm{H}} 2$ cytokine responses. Nature 464: 1362-1366.

Saenz SA, Siracusa MC, Monticelli LA, Ziegler CG, Kim BS, Brestoff JR, Peterson LW, Wherry EJ, Goldrath AW, Bhandoola A, et al. 2013. IL-25 simultaneously elicits distinct populations of innate lymphoid cells and multipotent progenitor type $2\left(\mathrm{MPP}^{\text {type2 }}\right)$ cells. J Exp Med 210: $1823-1837$.

Salimi M, Barlow JL, Saunders SP, Xue L, Gutowska-Owsiak D, Wang X, Huang LC, Johnson D, Scanlon ST, McKenzie AN, et al. 2013. A role for IL-25 and IL-33-driven type-2 innate lymphoid cells in atopic dermatitis. J Exp Med 210: 2939-2950.

Salmond RJ, Mirchandani AS, Besnard AG, Bain CC, Thomson NC, Liew FY. 2012. IL-33 induces innate lymphoid cell-mediated airway inflammation by activating mammalian target of rapamycin. J Allergy Clin Immunol 130: e1156.

Satoh-Takayama N, Lesjean-Pottier S, Vieira P, Sawa S, Eberl G, Vosshenrich CA, Di Santo JP. 2010. IL-7 and IL-15 independently program the differentiation of intestinal $\mathrm{CD}^{-} \mathrm{NKp} 46^{+}$cell subsets from Id2-dependent precursors. J Exp Med 207: 273-280.

Savinko T, Matikainen S, Saarialho-Kere U, Lehto M, Wang G, Lehtimaki S, Karisola P, Reunala T, Wolff H, Lauerma A, et al. 2012. IL-33 and ST2 in atopic dermatitis: Expression profiles and modulation by triggering factors. J Invest Dermatol 132: 1392-1400.

Schmitz J, Owyang A, Oldham E, Song Y, Murphy E, McClanahan TK, Zurawski G, Moshrefi M, Qin J, Li X, et al. 2005. IL-33, an interleukin-1-like cytokine that signals via the IL-1 receptor-related protein ST2 and induces $\mathrm{T}$ helper type 2-associated cytokines. Immunity 23: 479-490.

Shaw JL, Fakhri S, Citardi MJ, Porter PC, Corry DB, Kheradmand F, Liu YJ, Luong A. 2013. IL-33-responsive in nate lymphoid cells are an important source of IL-13 in chronic rhinosinusitis with nasal polyps. Am J Resp Crit Care Med 188: 432-439.

Shikotra A, Choy DF, Ohri CM, Doran E, Butler C, Hargadon B, Shelley M, Abbas AR, Austin CD, Jackman J, et al. 2012. Increased expression of immunoreactive thymic stromal lymphopoietin in patients with severe asthma. $J$ Allergy Clin Immunol 129: e101-109.

Sonnenberg GF. 2013. Editorial: New tricks for innate lymphoid cells. J Leukocyte Biol 94: 862-864.

Sonnenberg GF, Artis D. 2012. Innate lymphoid cell interactions with microbiota: Implications for intestinal health and disease. Immunity 37: 601-610.

Sonnenberg GF, Monticelli LA, Alenghat T, Fung TC, Hutnick NA, Kunisawa J, Shibata N, Grunberg S, Sinha R, Zahm AM, et al. 2012. Innate lymphoid cells promote anatomical containment of lymphoid-resident commensal bacteria. Science 336: 1321-1325.

Sonnenberg GF, Mjosberg J, Spits H, Artis D. 2013. SnapShot: Innate lymphoid cells. Immunity 39: 622-622.

Soumelis V, Reche PA, Kanzler H, Yuan W, Edward G, Homey B, Gilliet M, Ho S, Antonenko S, Lauerma A, et al. 2002. Human epithelial cells trigger dendritic cell mediated allergic inflammation by producing TSLP. Nat Immunol 3: 673-680.

Spits H, Cupedo T. 2012. Innate lymphoid cells: Emerging insights in development, lineage relationships, and function. Annu Rev Immunol 30: 647-675.

Spits H, Artis D, Colonna M, Diefenbach A, Di Santo JP, Eberl G, Koyasu S, Locksley RM, McKenzie AN, Mebius $\mathrm{RE}$, et al. 2013. Innate lymphoid cells-A proposal for uniform nomenclature. Nat Rev Immunol 13: 145-149.

Tait Wojno ED, Artis D. 2012. Innate lymphoid cells: Balancing immunity, inflammation, and tissue repair in the intestine. Cell Host Microbe 12: 445-457.

Turner JE, Morrison PJ, Wilhelm C, Wilson M, Ahlfors H, Renauld JC, Panzer U, Helmby H, Stockinger B. 2013. IL9-mediated survival of type 2 innate lymphoid cells promotes damage control in helminth-induced lung inflammation. J Exp Med 210: 2951-2965.

Walker JA, Barlow JL, McKenzie AN. 2013. Innate lymphoid cells-How did we miss them? Nat Rev Immunol 13: 75-87.

Wilhelm C, Hirota K, Stieglitz B, Van Snick J, Tolaini M, Lahl K, Sparwasser T, Helmby H, Stockinger B. 2011. An IL-9 
B.S. Kim and D. Artis

fate reporter demonstrates the induction of an innate IL-9 response in lung inflammation. Nat Immunol 12: $1071-1077$.

Wong SH, Walker JA, Jolin HE, Drynan LF, Hams E, Camelo A, Barlow JL, Neill DR, Panova V, Koch U, et al. 2012. Transcription factor $\mathrm{ROR} \alpha$ is critical for nuocyte development. Nat Immunol 13: 229-236.

Wu D, Molofsky AB, Liang HE, Ricardo-Gonzalez RR, Jouihan HA, Bando JK, Chawla A, Locksley RM. 2011 Eosinophils sustain adipose alternatively activated macrophages associated with glucose homeostasis. Science 332: $243-247$

Xue L, Salimi M, Panse I, Mjosberg JM, McKenzie AN, Spits H, Klenerman P, Ogg G. 2013. Prostaglandin D activates group 2 innate lymphoid cells through chemoattractant receptor-homologous molecule expressed on T2 cells. J Allergy Clin Immunol 133: 1184-1194.

Yang Q, Monticelli LA, Saenz SA, Chi AW, Sonnenberg GF, Tang J, De Obaldia ME, Bailis W, Bryson JL, Toscano K, et al. 2013. T cell factor 1 is required for group 2 innate lymphoid cell generation. Immunity 38: 694-704.

Yokota Y, Mansouri A, Mori S, Sugawara S, Adachi S, Nishikawa S, Gruss P. 1999. Development of peripheral lymphoid organs and natural killer cells depends on the helix-loop-helix inhibitor Id2. Nature 397: 702-706.

Yu X, Pappu R, Ramirez-Carrozzi V, Ota N, Caplazi P, Zhang J, Yan D, Xu M, Lee WP, Grogan JL. 2013. TNF superfamily member TL1A elicits type 2 innate lymphoid cells at mucosal barriers. Mucosal Immunol 7: $730-740$. 


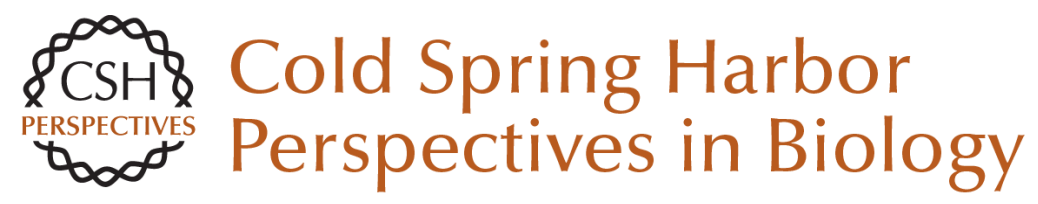

\section{Group 2 Innate Lymphoid Cells in Health and Disease}

Brian S. Kim and David Artis

Cold Spring Harb Perspect Biol 2015; doi: 10.1101/cshperspect.a016337 originally published online January 8, 2015

Subject Collection Innate Immunity and Inflammation

Group 2 Innate Lymphoid Cells in Health and Disease

Brian S. Kim and David Artis

Inflammation and the Blood Microvascular

System

Jordan S. Pober and William C. Sessa

Sinusoidal Immunity: Macrophages at the

Lymphohematopoietic Interface

Siamon Gordon, Annette Plüddemann and

Subhankar Mukhopadhyay

Allergic Inflammation--Innately Homeostatic Laurence E. Cheng and Richard M. Locksley

Approaching the Next Revolution? Evolutionary Integration of Neural and Immune Pathogen

Sensing and Response

Kevin J. Tracey

Inflammasomes

Marcel R. de Zoete, Noah W. Palm, Shu Zhu, et al.

IL-6 in Inflammation, Immunity, and Disease

Toshio Tanaka, Masashi Narazaki and Tadamitsu Kishimoto
The Chemokine System in Innate Immunity Caroline L. Sokol and Andrew D. Luster

Microbial Sensing by Toll-Like Receptors and Intracellular Nucleic Acid Sensors Surya Pandey, Taro Kawai and Shizuo Akira

Tumor Necrosis Factor Superfamily in Innate Immunity and Inflammation John Sedý, Vasileios Bekiaris and Carl F. Ware

\section{Emerging Principles Governing Signal} Transduction by Pattern-Recognition Receptors Jonathan C. Kagan and Gregory M. Barton

Lipid Mediators in the Resolution of Inflammation Charles N. Serhan, Nan Chiang, Jesmond Dalli, et al.

Transcriptional Control of Inflammatory

Responses

Stephen T. Smale and Gioacchino Natoli

DNA Degradation and Its Defects

Kohki Kawane, Kou Motani and Shigekazu Nagata

For additional articles in this collection, see http://cshperspectives.cshlp.org/cgi/collection/

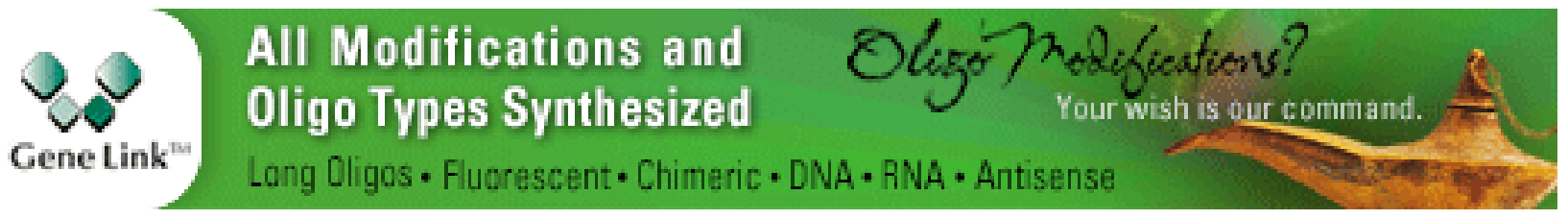

Copyright @ 2015 Cold Spring Harbor Laboratory Press; all rights reserved 